5 Eccles R, Jones AS. The effect of menthol on nasal resistance to airflow. 7 Laryngol Otol 1983;97:705-9.

Solow B, Greve E. Rhinomanometric recording in children. Rhinology 1980;18 exercise, hyperventilation and rebreathing. Acta Otolaryngol (Stockh) 1977

8 Vane JR. Inhibition of prostaglandin synthesis as a mechanism of action for aspirin-like drugs. Nature $1971 ; 231: 232-5$

9 Asad SI, Kemeny DM, Youlten LJF, Frankland AW, Lessof MH. Effect of Br Med 7 1984;288:745-8.

10 Asad SI, Youlten L JF, Lessof MH. Specific desensitisation in "aspirin sensitive" urticaria; plasma prostaglandin levels and clinical manifestations. Clin Allergy 1983;13:459-66. mucosa C'lin Otolaryngol $1983 \cdot 8: 159-63$.

eduani $R$. Eccles R Jones AS. A study of the synthesis and inactivation of prostagian, Eccles R, Jones AS. Effects of prostag nasal vasculature. Clin Otolaryngol (Stockh) 1983;8:337-41.

14 Änggard A. The effect of prostaglandins on nasal airway resistance in man. Ann Otol Rhinol Laryngol 1969;78:657-62.

(Accepted 6 February 1985)

\title{
Comparison of the antiemetics metoclopramide and promethazine in labour
}

\author{
LOUISE VELLA, DEBORAH FRANCIS, PETER HOULTON, FELICITY REYNOLDS
}

\begin{abstract}
A double blind trial was conducted in 477 mothers in labour to compare the antiemetics metoclopramide $10 \mathrm{mg}$ and promethazine $25 \mathrm{mg}$ and placebo when added to the first dose of pethidine. Metoclopramide and promethazine were equally effective, and both better than placebo, in reducing the incidence of nausea and vomiting after the administration of pethidine. Seventy seven per cent of mothers were drowsy, and $8 \%$ slept in the hour after the pethidine injection, with no difference between the groups. The sedative effect was more persistent in the promethazine group, $66 \%$ of whom were still drowsy after delivery. One third of the mothers in each group needed further analgesia, with $77 \%$ of these ultimately requesting an epidural. The reduction in pain half an hour and one hour after pethidine, assessed by a visual analogue scale, were, respectively, $22 \%$ and $22 \%$ for placebo $26 \%$ and $23 \%$ for metoclopramide; $13 \%$ and $9 \%$ for promethazine.
\end{abstract}

Analgesia after metoclopramide was significantly better than that after promethazine in terms of pain score, duration of first injection, and need for Entonox. Metoclopramide is therefore to be preferred to promethazine as an antiemetic in labour.

\section{Introduction}

Mothers being delivered at St Thomas's Hospital are offered a choice of analgesia, and although over $40 \%$ receive an epidural, $40^{\circ}$ initially choose pethidine. In centres where epidurals are not available round the clock pethidine is used more extensively, often combined with a phenothiazine derivative to counteract emesis. A combination of promethazine and pethidine has been popular for many years as a premedicant ${ }^{1}$ and in labour. ${ }^{2} 3$ Trials in other types of patients, however, have shown promethazine to be a profound and long acting sedative ${ }^{5}$ with an antianalgesic effect. ${ }^{6}$ Metoclopramide has been used as a

Anaesthetic Department, St Thomas's Hospital, London SE1 7EH LOUISE VELLA, FFARCS, lecturer

DEBORAH FRANCIS, MB, FFARCS, lecturer

PETER HOULTON, MB, FFARCS, lecturer

FELICITY REYNOLDS, MD, FFARCS, reader in pharmacology applied to anaesthesia

Correspondence and reprint requests to: Dr Felicity Reynolds. postoperative antiemetic since the 1960 s. $^{7}$ Many clinical trials in labour have investigated its effects on gastric emptying, ${ }^{8-10}$ but only one formally studied its antiemetic effect in comparison with perphenazine, with no investigation of its antinauseant properties. ${ }^{11}$ We examined the incidence of nausea and vomiting, sedation, and analgesia after metoclopramide, promethazine, and placebo given intramuscularly with the first dose of pethidine in a double blind trial in labour.

\section{Methods}

Patients requiring pethidine in labour, who gave their verbal consent, were included in the trial. Those with severe fetal abnormalities or intrauterine death diagnosed before delivery were excluded. With the first dose of pethidine $(100-150 \mathrm{mg})$ each patient was given a randomly coded ampoule containing either metoclopramide $10 \mathrm{mg}$, promethazine $25 \mathrm{mg}$, or saline $(2 \mathrm{ml})$ intramuscularly. This was termed the first injection. Any patient who needed further analgesia was given either pethidine alone or an epidural, as requested (the second injection). The occurrence of nausea, vomiting, and drowsiness or sleep was recorded by the midwife in the hour preceding the injection and in each subsequent hour until delivery or the next injection. Pain relief was assessed using the visual analogue pain score before and half an hour and one hour after the injection. The need for nitrous oxide plus oxygen (Entonox), oxytocin, or a further injection of antiemetic was also recorded.

A questionnaire relating to analgesia, sedation, and emesis was presented to the patient shortly after delivery.

The results were examined using $\chi^{2}$ test for numerical data; the standard error of each proportion was calculated from the formula:

$$
\operatorname{SE}\left(\frac{r}{n}\right)=\sqrt{\frac{1}{n}\left[\frac{r}{n} \times\left(1-\frac{r}{n}\right)\right]}
$$

the significance of the difference between proportions was calculated using the formula

$$
\left(\frac{r_{1}}{n_{1}}-\frac{r_{2}}{n_{2}}\right) / \sqrt{\frac{r_{1}}{n_{1}}+\frac{r_{2}}{n_{2}}\left(1-\frac{r_{1}}{n_{1}}+\frac{r_{2}}{n_{2}}\right)\left(\frac{1}{n_{1}}+\frac{1}{n_{2}}\right)}
$$

where $r=$ number of positive responders. Student's $t$ test was used to compare pain score.

\section{Results}

A total of 600 coded ampoules were used, but because of the mistaken inclusion of mothers who had already received antiemetics, delivery within an hour of the injection, or shortcomings in data collection, only 477 patients took part in the trial (metoclopramide 157, placebo 161 , promethazine 159 ).

There was no significant difference between the groups in age, 
parity, length of labour after the first injection, type of delivery, need for oxytocin, or severity of pain before analgesia (table I). The numbers of patients observed in each successive hour fell because of the onset of the second stage, the need for further analgesia, or human failing, until by four hours fewer than 70 patients remained in each group.

Nausea and vomiting-Both antiemetics prevented the increase in nausea and vomiting (fig 1 ) associated with pethidine and placebo, and by four hours promethazine produced a significant reduction in nausea from the level before pethidine administration $(p<0.05)$. There was no significant difference between the groups in the number of mothers given further antiemetic agents.

TABLE I-Clinical data

\begin{tabular}{|c|c|c|c|}
\hline & Placebo & Metoclopramide & Promethazine \\
\hline Total number of patients & 161 & 157 & 159 \\
\hline $\begin{array}{l}\quad \\
\quad \geqslant 1 \\
\text { No given oxytocin during labour }\end{array}$ & $\begin{array}{r}90 \\
71 \\
104\end{array}$ & $\begin{array}{r}96 \\
61 \\
116\end{array}$ & $\begin{array}{r}99 \\
60 \\
106\end{array}$ \\
\hline $\begin{array}{l}\text { Mean (SEM) pain score at first } \\
\text { injection }\end{array}$ & $7 \cdot 17(1.51)$ & $7 \cdot 36(1.40)$ & $7.09(1.56)$ \\
\hline $\begin{array}{l}\text { first injection and delivery (h) } \\
\text { Delivery (No of patients): }\end{array}$ & $4.71(0.30)$ & $5.50(0.36)$ & $5.02(0.29)$ \\
\hline $\begin{array}{l}\text { Spontaneous } \\
\text { Instrumental } \\
\text { Operative }\end{array}$ & $\begin{array}{r}125 \\
24 \\
12\end{array}$ & $\begin{array}{r}124 \\
23 \\
10\end{array}$ & $\begin{array}{r}124 \\
26 \\
9\end{array}$ \\
\hline
\end{tabular}

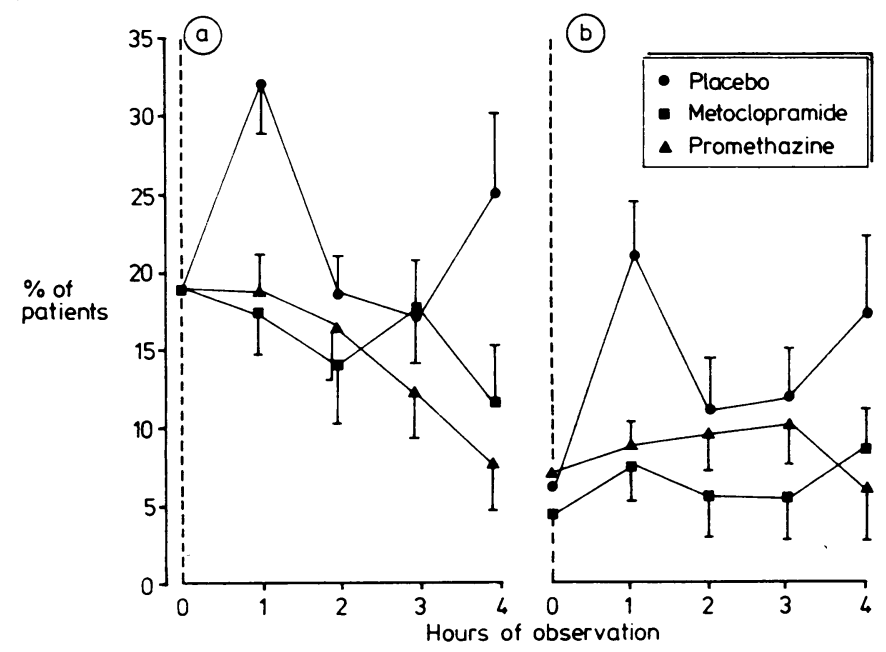

FIG 1-Percentage of patients with (a) nausea and (b) vomiting before (0) and in the four hours after injection of placebo, metoclopramide, and promethazine. Vertical bars represent standard errors of the proportions. Significantly more patients in the placebo group had nausea than in each other group in the first and fourth hours $p<0.001)$. The proportion vomiting in the placebo group was significantly different from that in the promethazine group in the first and fourth hours $(p<0.001)$, and from that in the metoclopramide group in the first $(p<0.001)$, second, third, and fourth hours $(p<0 \cdot 01)$

Sedation-During the first hour after the pethidine injection drowsiness increased from $9 \cdot 7^{\circ}$ o to $77 \%$ with $8^{\circ} \%$ actually sleeping, but with no difference between the groups (fig 2). During the second, third, and fourth hours significantly more drowsiness and sleep occurred after promethazine $(p<0.001)$, with no significant difference between metoclopramide and placebo.

Analgesia-The pain relief from pethidine was significantly less good with promethazine than with metoclopramide or placebo (fig 3). Moreover, significantly fewer mothers in the metoclopramide group required Entonox in the hours after injection than in the other groups $(\mathrm{p}<0.01$; table II). A similar number of women in each group asked for further analgesia, either epidural $\left(68^{\circ} \%\right)$ or pethidine $(32 \%)$, but more in the promethazine group chose epidural analgesia second time round $(p<0.05)$. Fifteen patients (eight taking metoclopramide) having opted for a second injection of pethidine, which was given alone, ultimately requested epidural analgesia. Thus of the patients who needed more than one dose of pethidine to take them through labour, $77^{\circ}$ o required epidural analgesia sooner or later. The duration of analgesia, measured as the time between the first and second injections, was longest with metoclopramide, and the difference between the metoclopramide and promethazine groups was significant $(p<0.05)$.

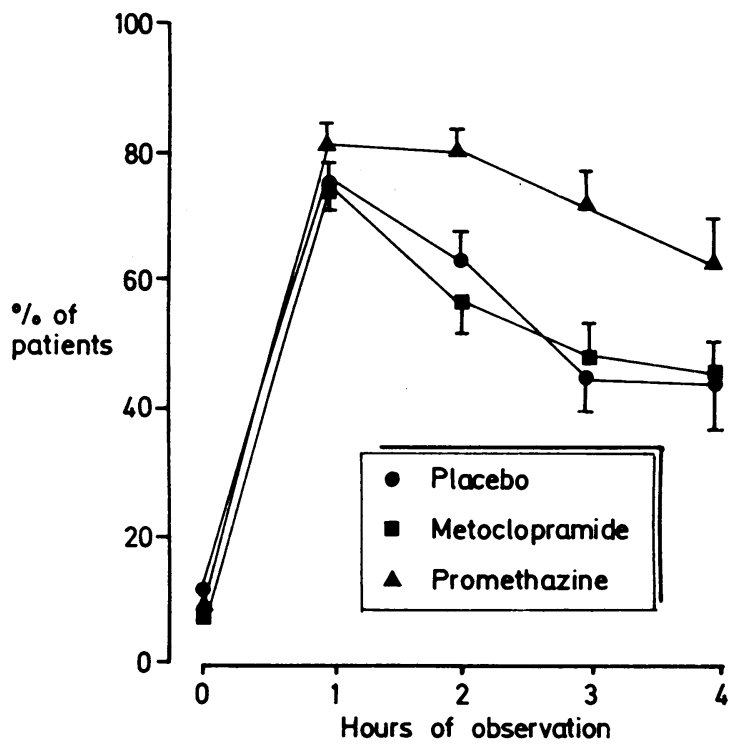

FIG 2-Percentage of patients who were sedated in the hour before $(0)$ and in the four hours after injection of pethidine plus placebo, metoclopramide, and promethazine. Vertical bars represent standard errors of the proportions.

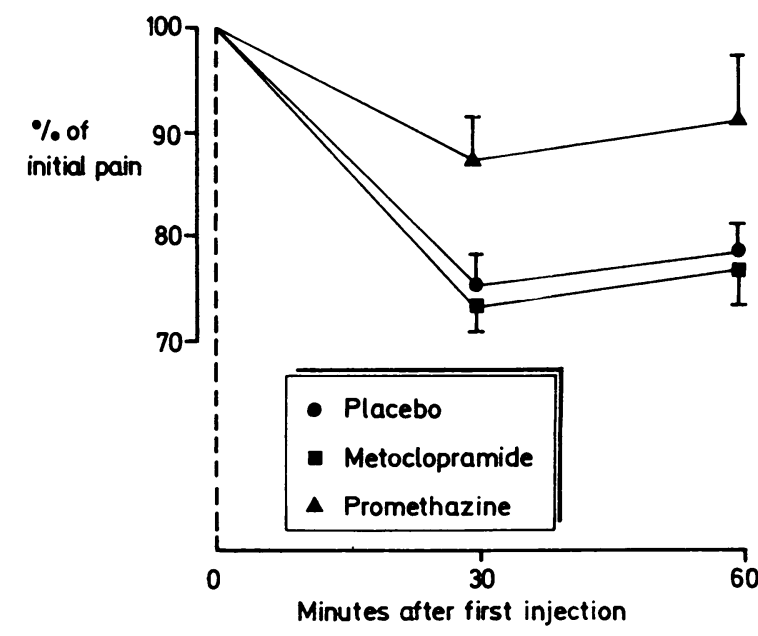

FIG 3-Pain score 30 and 60 minutes after injection of pethidine plus placebo, metoclopramide, or promethazine, presented as a percentage of the pain score at time 0 . The difference between promethazine and metoclopramide was significant at 30 minutes $(\mathrm{p}<0.01)$.

TABLE II-Details of analgesia

\begin{tabular}{lccc}
\hline & Placebo & Metoclopramide & Promethazine \\
\hline No of patients requiring Entonox & $74(46 \%)$ & $45(29 \%)$ & $67(42 \%)$ \\
No of patients requiring & $54(34 \%)$ & $52(33 \%)$ & $57(36 \%)$ \\
a second injection & 38 & 38 & 41 \\
$\quad$ Primiparas & 16 & 14 & 16 \\
$\quad$ Multiparas & 19 & 31 & 12 \\
$\quad$ No who had pethidine & 35 & 8 & 45 \\
$\quad$ No who had epidural & 4 & $8.52(0.09)$ & $3.60(0.07)$ \\
No requiring epidural as 3rd & injection & & \\
Mean (SEM) duration of first & $4.39(0.16)$ & 4.5 & \\
injection (h) & & &
\end{tabular}


Outcome-All babies were born alive, with no significant difference in Apgar scores between the groups (table III).

Patient questionnaire-Ninety seven per cent of subjects responded to the questionnaire, with no significant difference between the groups (table IV).

TABLE III-Mean Apgar scores in babies born to women in the three groups

\begin{tabular}{lccc}
\hline & Placebo & Metoclopramide & Promethazine \\
\hline 1 minute & 7.56 & 7.73 & 7.68 \\
5 minutes & 8.92 & 9.09 & 9.07 \\
\hline
\end{tabular}

TABLE IV-Results of patients' questionnaire

\begin{tabular}{|c|c|c|c|}
\hline & \multicolumn{3}{|c|}{${ }_{\circ}^{\circ}$ Of positive responses } \\
\hline & Placebo & Metoclopramide & Promethazine \\
\hline \multicolumn{4}{|l|}{ Pain relief in labour } \\
\hline Satisfactory & $30 \cdot 4$ & $35 \cdot 8$ & $32 \cdot 7$ \\
\hline Fair & $38 \cdot 6$ & $43 \cdot 0$ & $42 \cdot 3$ \\
\hline \multirow{2}{*}{\multicolumn{4}{|c|}{ Pain relief during delivery }} \\
\hline & & & \\
\hline Satisfactory & $39 \cdot 2$ & 43.9 & $49 \cdot 3$ \\
\hline $\begin{array}{l}\text { Fair } \\
\text { Unsatisfactory }\end{array}$ & $26 \cdot 5$ & $28 \cdot 05$ & $29 \cdot 6$ \\
\hline \multicolumn{4}{|l|}{ During labour: } \\
\hline $\begin{array}{l}\text { During labour: } \\
\text { Did you feel sick? }\end{array}$ & $54 \cdot 1^{* *}$ & $38 \cdot 7$ & $38 \cdot 8$ \\
\hline Did you vomit? & $35 \cdot 2 * *$ & $23 \cdot 3$ & $21 \cdot 1$ \\
\hline \\
\hline $\begin{array}{l}\text { Did you feel sick ? } \\
\text { Did you vomit? }\end{array}$ & $25 \cdot 7$ & $30 \cdot 5$ & $23 \cdot 8$ \\
\hline \multicolumn{4}{|l|}{ During labour: } \\
\hline Were you sleepy? & $79 \cdot 1$ & $78 \cdot 5$ & $86 \cdot 7$ \\
\hline $\begin{array}{l}\text { Did you sleep? } \\
\text { Do you feel drowsy now? }\end{array}$ & $\begin{array}{l}23 \cdot 6 \\
49 \cdot 0\end{array}$ & $26 \cdot 0$ & $\begin{array}{l}35 \cdot 9 * \\
65 \cdot 8^{* *}\end{array}$ \\
\hline \multirow{2}{*}{$\begin{array}{l}\text { Woud you have liked another } \\
\text { form of pain relief? }\end{array}$} & & & \\
\hline & $37 \cdot 2$ & $40 \cdot 7$ & $40 \cdot 7$ \\
\hline
\end{tabular}

$* \mathrm{p}=0.05 ; * * \mathrm{p}=0.01$

\section{Discussion}

The inclusion of a control period of observation allowed some assessment of the performance of pethidine itself, which appeared in this study to be more effective in inducing sedation, nausea, and vomiting than in relieving pain.

Nausea and vomiting-Conner et al found that promethazine did not protect against nausea associated with morphine. ${ }^{5}$ In our present trial both metoclopramide and promethazine prevented the increase in nausea and vomiting associated with pethidine administration, with promethazine having a more sustained effect. The patients' memories of nausea and vomiting during labour were consistent with the midwives' findingsthat the two antiemetics were equally effective and better than placebo. In a similar trial which showed the antiemetic and sedative effects of promazine, the mothers' memories neither correlated with the midwives' findings nor distinguished between promazine and placebo. ${ }^{12}$ In our study the overall incidence of both nausea and vomiting was higher when assessed in the patients' questionnaire because it covered a longer time span than the period studied by the midwives. The incidence of vomiting at delivery was related to the fact that all patients, except those delivered by caesarean section, received ergometrine in the form of Syntometrine at delivery. While metoclopramide is a selective dopaminergic $\left(\mathrm{D}_{2}\right)$ blocker in the chemoreceptor trigger zone, promethazine acts principally as a histamine $\left(\mathrm{H}_{1}\right)$ antagonist and anticholinergic in the vomiting centre complex. ${ }^{1: 3}$ It has been suggested that a combined dopaminergic and $\mathrm{H}_{1}$-cholinergic blocker might be the most effective antiemetic. " 4 Perphenazine, however, a phenothiazine which possesses both these actions, was no more effective than metoclopramide in reducing vomiting in labour, ${ }^{11}$ though the incidence of nausea was not investigated.

Sedation-Pethidine itself caused significant drowsiness in the first hour. The well recognised sedative effect of prometha- zine ${ }^{5}$ borne out by both the midwives' and patients' questionnaires, only became apparent in subsequent hours, and indeed persisted after delivery (table IV). Pethidine is much shorter acting than promethazine. It is clearly disadvantageous if a mother who receives promethazine in early labour and later opts for epidural analgesia loses the benefit of alertness. Metoclopramide was free from sedative effect.

Analgesia-That two thirds of the patients required only a single analgesic injection suggests that in many patients labour was progressing rapidly and therefore becoming increasingly painful. Nevertheless, the reduction in pain score at 30 minutes of only $24 \%$, even with the exclusion of the promethazine group, is in stark distinction to the $80-90 \%$ reduction in pain reported after epidural blockade using the same technique of assessment. ${ }^{15-17}$ When promethazine was added to pethidine pain relief was barely perceptible. Despite the wide use of promethazine, this is the first demonstration of its antianalgesic effect in labour, no earlier workers having used the visual analogue scale to measure pain. The reduced apparent duration of pethidine "analgesia" in the promethazine group and the larger number of patients choosing an epidural analgesic as the second injection are further confirmation of the antianalgesic effect of promethazine. Our results suggest that, by contrast, metoclopramide may have slightly potentiated pethidine analgesia, in the improved pain score at 30 minutes, the increased apparent duration of effect of pethidine, and the smaller number of patients requiring Entonox or opting for epidural analgesia second time round. The mothers' opinion of the analgesia did not differ significantly between the groups, most being either satisfied or fairly satisfied. Nature's amnesia is well recognised in parturition. The increased number who were satisfied at delivery reflects the fact that $78 \%$ of these had by then received an epidural.

Our results suggest that metoclopramide is to be preferred to promethazine for combination with pethidine in labour for the sake of improved analgesia and less sedation. Both are effective in counteracting nausea and vomiting, and while a combination of dopamine and $\mathrm{H}_{1}$ antagonist might be more so, it would, of course, possess the sedative effect common to the latter group.

We thank the conscientious midwives at St Thomas's Hospital, who completed the forms; Mr A Swan for statistical advice, the statisticians of the community medicine department for help with computing, the pharmacists for preparing coded ampoules, and the obstetricians for permission to carry out this trial on their patients.

\section{References}

1 Hopkin DAB, Hurter D, Jones CM. Promethazine and pethidine in anaesthesia. A new approach to pre-anaesthetic medication. Anaesthesia 1957;12:276-9. A new approach to pre-anasen C K C in obstetrical analgesia. $\mathcal{F} A M A \quad 1962 ; 181: 290-4$.

3 McQuitty FM. Relief of pain in labour. Fournal of Obstetrics and Gynaecology of the British Commonwealth 1967;74:925-8.

4 Keats AS, Telford J, Kuroso Y. Potentiation of meperidine by promethazine. Anaesthesiology 1961;22:34-4

Conner OT, Weldon Bellville J, Wender R, Wapner $S$, Dorey FJ, Katz RL Morphine and promethazine as intravenous premedicants. Anaesthesia and Analgesia $1977 ; 56: 801-7$.

W. Alterations in response to somatic pain associated with anaesthesia V: effect of promethazine. Br $\mathcal{F}$ Anaesth $1961 ; 33: 3-8$.

7 Bauer A. The antiemetic effect of metoclopramide in major surgery In: International symposium on gastro-duodeno-jejunal dyskinesia. Vichy:73-4.

national symposium on gastro-duodeno-jejunal dyskinesia. Vichy:73-4.
Howard FA, Sharp DS. The effect of intramuscular metoclopramide on gastric emptying during labour. Postgrad Med $\mathcal{F} 1973 ; 49$ (suppl 4):53-7.

Nimmo WS, Wilson J, Prescott LF. Narcotic analgesics and delayed gastric emptying during labour. Lancet $1975 ; \mathrm{i}: 890-3$.

10 Murphy DF, Nally B, Gardiner J, Unwin A. Effect of metoclopramide on gastric emptying before elective and emergency Caeserean section. $B r \quad f$ Anaest $1984 ; 56: 1113-6$

11 McGarry JM. A double-blind comparison of the antiemetic effect during labour of metoclopramide and perphenazine. Br $\mathcal{F}$ Anaesth 1971;43:613-5. ii:423-7.

13 Petroutka SJ, Synder SH. Antiemetics: neurotransmitter receptor binding predicts therapeutic action. Lancet $1982 ; \mathrm{i}: 658-9$.

4 Howard W'V. Post-operative vomiting. Anaesthesia $1984 ; 39: 1035$

15 Justins D, Francis DM, Houlton PG, Reynolds F. A controlled trial of extradural fentanyl in labour. Br $\mathcal{F}$ Anaesth 1982;54:409-1

16 Justins DM, Knott C, Luthman J, Reynolds F. Epidural versus intramuscular fentanyl. Analgesia and pharmacokinetics in labour. Anaesthesia 1983;38.

7 Rickford WJK, Reynolds F. Epidural analgesia in labour and maternal posture. Anaesthesia 1983;38:1169-74.

(Accepted 8 February 1985) 